\title{
EOSINOPHILIC MYOCARDITIS ASSOCIATED WITH VISCERAL LARVA MIGRANS CAUSED BY TOXOCARA CANIS INFECTION
}

\author{
JI HEE KIM, MD, WOO-BAEK CHUNG, MD, KYUNG-YOON CHANG, MD, SUN-YOUNG Ko, MD, \\ MI-HEE PARK, MD, YOUNG-KYOUNG SA, MD, YUN-SEOK CHOI, MD, PHD, \\ CHUL-SOO PARK, MD, PHD AND MAN-YOUNG LEE, MD, PHD

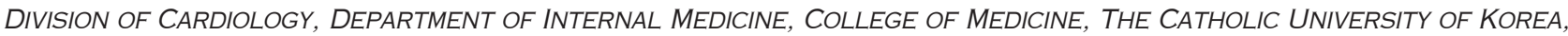 \\ SEOUL, KOREA
}

A 41-year-old woman who was diagnosed with myocarditis presented eosinophilia. Since the antibody against Toxocara canis (T. canis) was positive, we diagnosed that she had visceral larva migrans due to T. canis associated with myocarditis. She was treated with oral albendazole and prednisolone for two weeks, eosinophil count and hepatic enzymes were normalized after completion of treatment. This is the first report of myocarditis caused by T. canis infection in Korea.

KEY WORDS: Eosinophilic myocarditis · Toxocara canis · Visceral larva migrans.

\section{INTRODUCTION}

Toxocara canis (T. canis), a common dog roundworm, is one of the causative agents of visceral larva migrans (VLM). When infective eggs of $T$. canis reach the human gastrointestinal tract, they enter the portal system and reach the liver. Some larvae then migrate from the liver to the lung and the heart through the systemic circulation. Myocarditis may occur in 10-15\% of cases of VLM, and in those cases, myocarditis is accompanied by an increased level of circulating eosinophils. There have been approximately 10 cases of myocarditis associated with toxocara infection and only 2 cases were found in English publication since the year 2000. This is the first report in Korea. Here, we present case of myocarditis associated with eosinophilia caused by $T$. canis VLM.

\section{CASE}

A 41-year-old woman presented at our hospital complaining of chest discomfort and pain. She had been healthy with no significant preceding symptoms, allergic history or past medical history.

The initial examination showed the following findings; body temperature $37.8^{\circ} \mathrm{C}$, blood pressure $94 / 60 \mathrm{mmHg}$, heart rate
100 beats/min and a cardiac gallop rhythm.

Laboratory data on admission revealed decrease in the total white blood cell count $\left(1040 / \mathrm{mm}^{3}\right)$, elevated enzymes (creatinine phosphokinase $236 \mathrm{IU} / \mathrm{L}$, aspartate aminotransferase 112 IU/L, alanine aminotransferase $87 \mathrm{IU} / \mathrm{L}$, lactic dehydrogenase $588 \mathrm{IU} / \mathrm{L}$, Troponin-I $4.070 \mathrm{ng} / \mathrm{mL}, \mathrm{CK}-\mathrm{MB} 12.32 \mathrm{ng} / \mathrm{mL}$ and proBNP $8760 \mathrm{pg} / \mathrm{mL}$ ). Electrocardiogram (ECG) showed a regular sinus rhythm with low voltage in all limb and precordial leads (Fig. 1). Transthoracic echocardiogram (TTE) showed marked edematous left ventricular (LV) myocardium

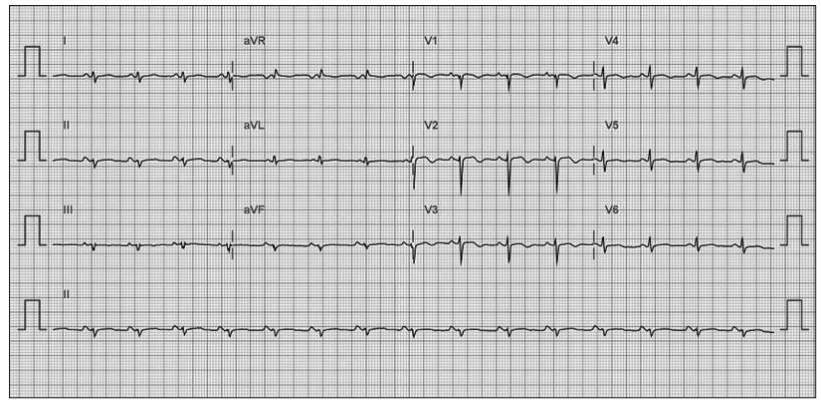

Fig. 1. Twelve-lead electrocardiogram reveals regular sinus rhythm with low voltage.

\footnotetext{
Received: April 24, 2012 •Revised: July 7, 2012 •Accepted: August 8, 2012

Address for Correspondence: Woo-Baek Chung, Division of Cardiology, Department of Internal Medicine, College of Medicine, The Catholic University of Korea, Yeouido St. Mary's Hospital, 10 63-ro, Yeongdeungpo-gu, Seoul 150-713, Korea

Tel: +82-2-3779-1325, Fax: +82-2-780-3132, E-mail: peace816@catholic.ac.kr

- This is an Open Access article distributed under the terms of the Creative Commons Attribution Non-Commercial License (http://creativecommons.org/licenses/by-nc/3.0) which permits unrestricted non-commercial use, distribution, and reproduction in any medium, provided the original work is properly cited.
} 
and global hypokinesis (Fig. 2A), resulted in mild left ventricular systolic dysfunction (LV ejection fraction $=48 \%)($ Fig. 2B). There was no significant valvular dysfunction and small pericardial effusion without tamponade physiology was noted. We diagnosed that she had acute myocarditis of unknown etiology. Empirical treatment such as intravenous antibiotics injection, bed rest, pain control and close vital sign monitoring were performed. On the tenth day of admission, total white blood cell count $\left(17160 / \mathrm{mm}^{3}\right)$ and eosinophil count (8430/ $\mathrm{mm}^{3}$ ) markedly increased ( $49 \%$ of her total white blood cell count). We started oral administration of prednisolone $1 \mathrm{mg} /$ $\mathrm{kg}$ for 3 days and performed ventricular endomyocardial biopsy. Histopathologic findings revealed myocyte necrosis and degeneration (Fig. 3). The antibody test against parasitic infection demonstrated that toxocara immunoglobulin $\mathrm{G}$ ( $\mathrm{IgG}$ ) was positive. Taken together, we diagnosed that she had myocarditis caused by $T$. canis VLM. We started oral administration of albendazol $400 \mathrm{mg}$ twice a day for two weeks after oral prednisolone $1 \mathrm{mg} / \mathrm{kg}$ administration for 3 days. Three days after starting steroid therapy, eosinophil count decreased promptly $\left(130 / \mathrm{mm}^{3}\right)$. One week after steroid therapy, TTE was followed up. TTE finding showed that echogenicity of LV myocardium was markedly decreased and wall thickness was normalized (Fig. 2C). M mode evaluation of LV showed completely recovered myocardial contractility (Fig. 2D). After the completion of the treatment, physical examination, laboratory tests, ECG and echocardiogram showed no abnormal findings and she was able to return to work.

\section{DISCUSSION}

Human toxocariasis is a helminthozoonosis due to the migration of Toxocara species larvae through human organism. Many reviews from Western countries indicated that children under 12 years old, who often play outside, are the most affected age group for toxocariasis. ${ }^{12)}$ They are accidentally infected with T. canis eggs, which expelled in feces puppies and fully develop in the surrounding environment within two to four weeks. Human become infected by ingesting either embryonated eggs from soil (geophagia, pica), dirty hands or raw vegetables, or larvae from undercooked giblets.

When embryonated eggs of $T$. canis reach the human gastrointestinal tract, they hatch and enter the portal system, reaching the liver. Some larvae then migrate to the lungs and heart through the systemic circulation. ${ }^{3)}$ In this case, we could not find obvious source for T. canis infection. She didn't have any history of raising a dog or eating undercooked giblets. We as-
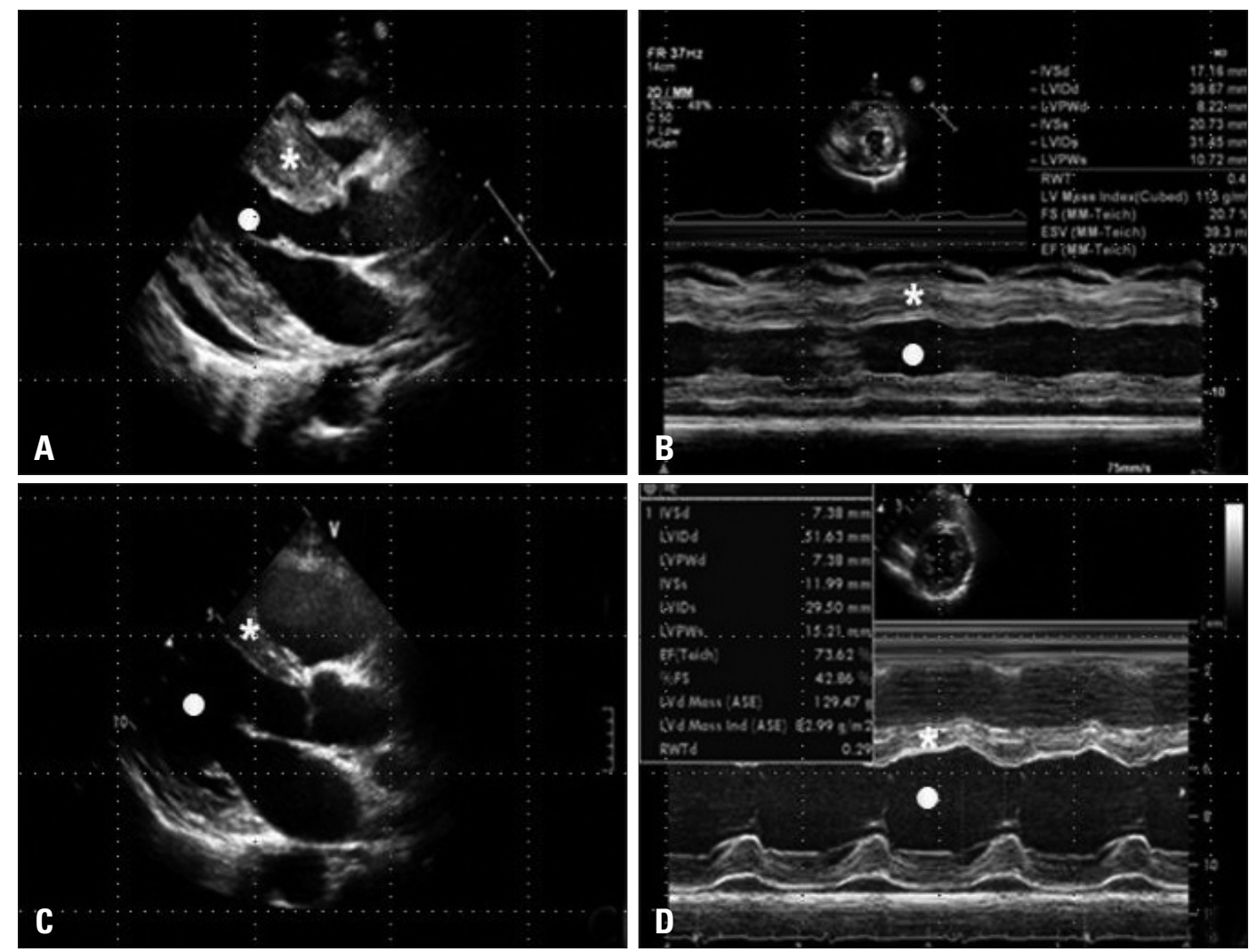

Fig. 2. Transthoracic echocardiogram (TTE). A: Parasternal long axis view of TTE showed edematous myocardium with increased echogenicity and small pericardial effusion. B: M-mode image of mid ventricular level of left ventricle showed decreased contractility. C: Follow-up TTE after treatment showed markedly decreased echogenicity of myocardium and pericardial effusion. D: M-mode image also showed normalized left ventricular (LV) wall thickness and recovered LV contractility after steroid therapy. *: interventricular septum, $\bullet$ : left ventricular cavity. 

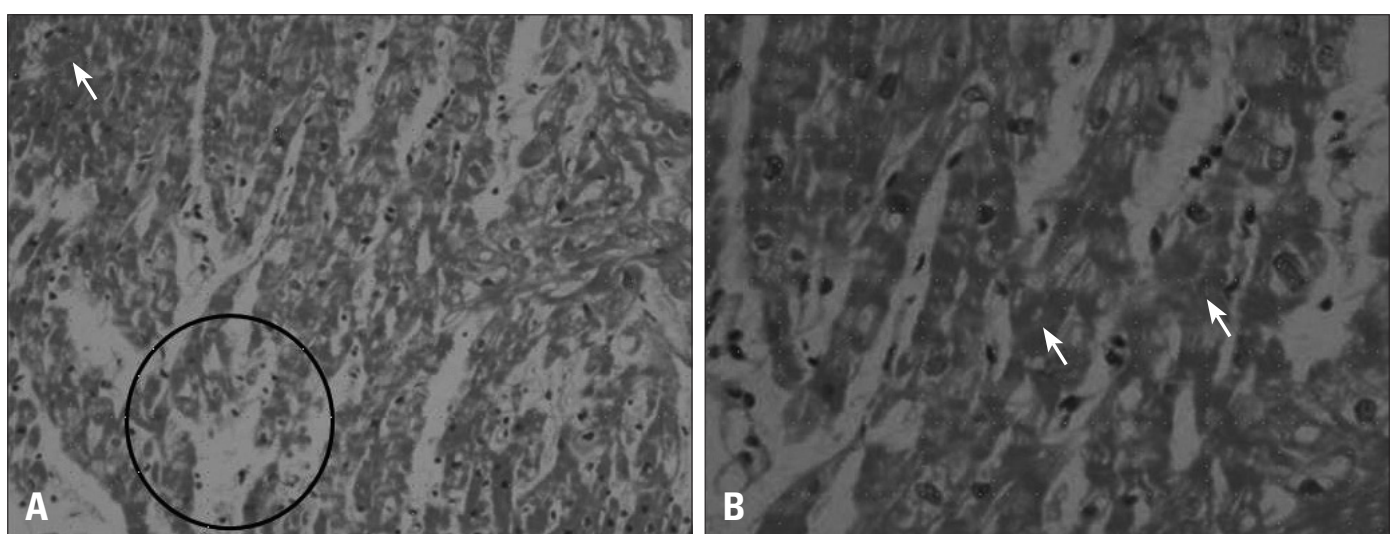

Fig. 3. Myocardial biopsy microscopic finding (after three days of treatment with prednisolone) shows myocyte necrosis and degeneration [H\&E stain, $(\mathrm{A}) \times 100,(B) \times 400]$. $\leftarrow$ : myocyte necrosis, $\circ$ : myocyte degeneration.

sumed that she infected by ingesting embryonated eggs or larvae from raw vegetables, such as lettuce.

A definitive laboratory diagnosis of human toxocaral infection can be achieved by pathology examination of various organ specimens. However, such a direct parasitologic assessment is awkward and uncommon, serologic methods are the mainstay for the diagnosis. The most commonly utilized diagnostic serologic test is the enzyme-linked immunosorbent assay with Toxocara excretory secretory antigen. But when interpreting a serologic result, it should be kept in mind that the numerous seropositive individuals detected through screening of large populations in epidemiological surveys probably represent past rather than recent infection. A single seropositivity therefore has limited pathological significance. Immunologic testing therefore, should be accompanied by a blood eosinophil count and if possible, by determination of serum total immunoglobulin E.4) $\mathrm{A}$ finding of both a peripheral eosinophilia and a positive serologic test result is indicative of active toxocariasis. ${ }^{5)}$

Myocarditis in VLM may result from direct larval invasion to the myocardium and/or hypersensitivity reactions to the parasites. ${ }^{6)}$ It has been suggested that there are 3 clinical stages of eosinophilic myocarditis: acute necrotizing phase, thrombotic phase and endomyocardial fibrosis phase. Loffler's endomyocarditis is considered to correspond to the second stage of eosinophilic endomyocardial disease.

The third stage probably corresponds to restrictive myocarditis." Differential diagnoses include other types of myocarditis, Churg-Strauss syndrome, hypersensitivity reaction, malignant diseases, parasitic infection or hypereosinophilic syndrome.

TTE finding shows diverse feature including diffuse severe hypokinesia or left ventricular focal asynergy. ${ }^{8}$ In our case, LV diastology did not showed significant dysfunction except abnormal relaxation. We think mild decreased LV systolic function, (left ventricle ejection fraction $=48 \%$ ) was the reason. Thrombus also can occur and according to its characteristics, not only anticoagulation therapy but also surgical removal of the thrombus should be considered to prevent systemic embo- lism.910)

Therapy is primarily based upon administration of anthelmintics. Albendazole is a benzimidazole anthelmintic and is used as treatment for various parasitic infections. Currently, 5 days or more use of albendazole $800 \mathrm{mg} /$ day or $10 \mathrm{mg} / \mathrm{kg} /$ day are recommended for treatment of $T$. canis infection. The mechanism of its anthelmintic action is inhibition of tubulin polymerization and microtubule-dependent glucose uptake inhibition.

In this case, for the control of aggravated eosinophilia, we started administration of prednisolone. Because she didn't have cardiac tamponade, cardiogenic shock or pulmonary edema, prednisolone was administered at $1.0 \mathrm{mg} / \mathrm{kg} / \mathrm{day}{ }^{8)}$ And as soon as we confirmed toxocara IgG positive, albendazole was added to the medication. The combination therapy with prednisolone and albendazole was effective.

When a patient who has myocarditis with eosinophilia occurs, toxocara infection should be considered for possible cause.

\section{REFERENCES}

1. Woodruff AW. Toxocariasis. Br Med J 1970;3:663-9.

2. Parasitic zoonoses. Report of a WHO expert committee with the participation of FAO. World Health Organ Tech Rep Ser 1979:1-107.

3. Enko K, Tada T, Ohgo KO, Nagase S, Nakamura K, Ohta K, Ichiba S, Ujike Y, Nawa Y, Maruyama H, Ohe T, Kusano KF. Fulminant eosinophilic myocarditis associated with visceral larva migrans caused by Toxocara canis infection. Circ J 2009;73:1344-8.

4. Schantz PM, Glickman LT. Toxocaral visceral larva migrans. N Engl J Med 1978;298:436-9.

5. Magnaval JF, Glickman LT, Dorchies P, Morassin B. Highlights of buman toxocariasis. Korean J Parasitol 2001;39:1-11.

6. Abe K, Shimokawa H, Kubota T, Nawa Y, Takeshita A. Myocarditis associated with visceral larva migrans due to Toxocara canis. Intern Med 2002;41:706-8.

7. Brockington IF, Olsen EG. Eosinophilia and endomyocardial fibrosis. Postgrad Med J 1972;48:740-1.

8. Kawano S, Kato J, Kawano N, Yoshimura Y, Masuyama H, Fukunaga T, Sato Y, Maruyama H, Mihara K, Ueda A, Toyoda K, Imamura T, Kitamura K. Clinical features and outcomes of eosinophilic myocarditis patients treated with prednisolone at a single institution over a 27-year period. Intern Med 2011;50:975-81. 
9. Jang $\mathrm{YB}, \mathrm{Rhee} \mathrm{KS}, \mathrm{Ko} \mathrm{JK}$. A case of surgical removal of a bypermobile left ventricular thrombus complicated to acute myocarditis. J Korean Soc Echocardiogr 2004;12:39-41.

10. Sohn IS, Park JC, Hong SN, Lim SY, Lee SR, Kim KH, Park HW,
Hong YJ, Kim JH, Kim W, Ahn Y, Jeong MH, Cho JG, Kang JC. A case of surgically removed left ventricular thrombus complicated to acute myocarditis. J Korean Soc Echocardiogr 2005;13:128-30. 